Journal of Reproduction and Development, Vol. 39, No. 1, 1993

\title{
Motility and Penetrability into Zona-Free Hamster Eggs of Boar Spermatozoa Collected from Various Regions of the Epididymis
}

\author{
Hiroshi HARAYAMA, Hiroshi KUSUNOKI ${ }^{1)}$ and \\ Seishiro KATO') \\ Graduate School of Science and Technology \\ and ${ }^{1)}$ Faculty of Agriculture, Kobe University, \\ Kobe 657, Japan
}

\begin{abstract}
The objectives of the present study are to characterize the motility and penetrability into zona-free hamster eggs of boar spermatozoa from 7 regions of the epididymis. Spermatozoa from the caput epididymidis were immotile or exhibited a flagellant or circular type of movement. However, $80 \%$ of the cells from the proximal cauda showed an intensive, forward movement. When the spermatozoa from each region of the epididymis were coincubated with zona-free hamster eggs after preincubation for inducing the acrosome reaction, they exhibited high penetration rates (95-100\%) and average number of spermatozoa (3.4-5.8) in penetrated eggs irrespective of their origin. These findings indicate that most of the spermatozoa acquire the ability to exhibit progressive motility during their transit through the corpus, and that at least some of the cells located in the proximal caput have the ability to fuse with egg plasma membrane.
\end{abstract}

Key words: Boar, Epididymal Spermatozoa, Zona-free hamster egg, Motility, Sperm penetration assay.

(J. Reprod. Dev. 39: 41-45, 1993)

n mammals, the epididymal region where spermatozoa acquire fertilizing ability is different among the species [1]. In a literature examining the fertilizing ability of boar spermatozoa from different regions of the epididymis using artificial insemination [2], it has been shown that the majority of spermatozoa acquire the ability during their transit through the corpus epididymidis, although a low proportion of the cells from the caput already possess it. The fertilizing ability of a spermatozoon is thought to be governed by various factors: Sufficient motility to ascend to the ampulla of the oviduct and to transit through the cumulus oophorous and zona pellucida of an egg: The ability to bind to the zona pellucida and to egg plasma membrane: The capacity to undergo capacitation and subsequent acrosome reaction, and to fuse with egg plasma membrane [3]. A spermatozoon lacking at least one of the above factors

Accepted for Publication: November 30, 1992

Correspondence: H. Harayama is not capable of fertilizing the egg in vivo. Recently, epididymal regions where spermatozoa develop each factor have been determined in the mouse [4-7], hamster [8], rabbit [9] and ram [10-12]. To our knowledge, however, only limited data on boars are available [13].

Removal of the zona pellucida allows spermatozoa of a large variety of species including the boar to penetrate the hamster egg [14]. Since vigorous motility of spermatozoa is not essential for penetration into zona-free hamster eggs [15], the cross-species sperm penetration assay using zonafree hamster eggs is potentially a useful indicator of the fusability with egg plasma membrane [16, 17].

The objectives of the present study were to characterize motility and penetrability into zonafree hamster eggs of boar spermatozoa collected from various regions of the epididymis. 


\section{Materials and Methods}

\section{Collection of spermatozoa from the epididymis}

The three mature Chinese Meishan boars were housed under natural conditions of day length and temperature, and given a formula feed for meat production testing (Nihon Nosan Kogyo Co., Yokohama, Japan). After they were slaughtered, the testis-epididymides were collected. Within 5 min after collection, the epididymal arteries and veins were perfused with approximately $30 \mathrm{ml}$ of saline by way of the spermatic and epididymal arteries. The epididymides were divided into 7 regions (Fig. 1). Tissue samples from the 6 upper regions (Regions 1-6 in Fig. 1) were placed in the Petri dishes containing $10 \mathrm{ml}$ of $\mathrm{K} 3$ medium composed of $125.83 \mathrm{mM} \mathrm{NaCl}, 2.25 \mathrm{mM} \mathrm{CaCl}_{2}$ and $37.00 \mathrm{mM} \mathrm{NaHCO}{ }_{3}$ [18], coarsely minced using razor blades and kept at room temperature for $10 \mathrm{~min}$. After removal of the minced tissue, the sperm samples were centrifuged at about $150 \times \mathrm{g}$ for $1 \mathrm{~min}$ to remove tissue debris and hemocytes. The contents of the distal cauda (Region 7 in Fig. 1) were displaced in a retrograde manner by gentle air pressure after a needle attached to a syringe was inserted into the ductus deferens and were diluted with $\mathrm{K} 3$ medium.

\section{Motility estimation}

Sperm motility was estimated subjectively in a small drop of each of the samples under a coverslip using a bright-field microscope $(\times 100$ and $\times 400)$ equipped with a heated stage $(37 \mathrm{C})$. Spermatozoa were considered motile irrespective of the type of movement such as uncoordinated twitching, intensive flagellant, circular and progressive movement, and only advancing cells were

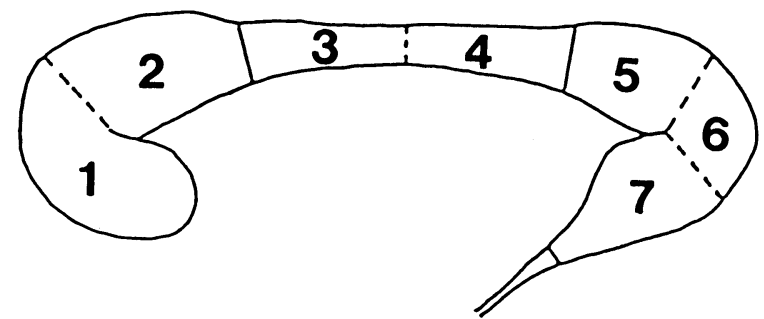

Fig. 1. Diagram showing the regions into which the epididymis was divided. 1: Proximal caput, 2: Distal caput, 3: Proximal corpus, 4: Distal corpus, 5: Proximal cauda, 6: Central cauda, 7: Distal cauda. regarded as progressively motile spermatozoa. Percentages of motile spermatozoa and progressively motile cells were graded in increments of $5 \%$.

\section{Sperm penetration assay}

The sperm samples were washed 3 times by centrifugation at $600 \times \mathrm{g}$ for $5 \mathrm{~min}$ using a $\mathrm{K} 3$ medium and preincubated for induction of the acrosome reaction, as previously described in ejaculated spermatozoa of the goat [18] and boar [19]. Briefly, the sperm pellet was resuspended in a small volume of the supernatants to give a concentration of approximately $4.0 \times 10^{9}$ cells $/ \mathrm{ml}$, and the sperm suspension was introduced into the lumen of a glass tube $(1.0 \mathrm{~mm}$ i.d., $2.0 \mathrm{~mm}$ o.d.), and then both terminals of the tube were sealed with a mixture of vaseline and paraffin. The spermatozoa in the tube were preincubated at 39.5 $\mathrm{C}$ for $2 \mathrm{~h}$, and then transferred by gentle air pressure to a test tube containing a medium developed by Brackett and Oliphant [20] (BO medium). After being evaluated for sperm motility, the spermatozoa were diluted again at a concentration of $1.0 \times 10^{7} \mathrm{cells} / \mathrm{ml}$ with $\mathrm{BO}$ medium for insemination.

Zona-free hamster eggs were prepared as described below. Mature female golden hamsters were induced to superovulate by intraperitoneal injection of 30 IU PMSG (Serotropin: TeikokuZoki Co.), followed 51-54 h later by an intraperitoneal injection of $30 \mathrm{IU}$ hCG (Puberogen: Sankyo Co.), and killed 15-17 h after hCG injection for recovery of eggs. Eggs recovered from the ampullary portion of the oviducts were treated with $0.1 \%$ (W/V) hyaluronidase (Type I: Sigma Chemical Co.) to remove the cumulus oophorus. The eggs were then washed 3 times with fresh $\mathrm{BO}$ medium, transferred to a droplet containing $0.05 \%(\mathrm{~W} / \mathrm{V})$ trypsin (Type III: Sigma Chemical Co.) to dissolve the zona pellucida and then washed 3 times with BO medium. Groups of about 10 eggs each were transferred into $0.35-\mathrm{ml}$ droplets of $\mathrm{BO}$ medium under paraffin oil in a plastic culture dish.

Insemination was performed by adding $0.05 \mathrm{ml}$ of the prepared sperm suspension. After 5-h coincubation $\left(5 \% \mathrm{CO}_{2}\right.$ in air at $\left.37 \mathrm{C}\right)$, the eggs were washed with $\mathrm{BO}$ medium by gentle and repeated aspiration with a Pasteur pipette, mounted on a glass slide, fixed with $10 \%$ formalin in phosphate-buffered saline and stained with 
lacmoid. The presence of an enlarged sperm head(s) and/or male pronucleus(ei) with its tail(s) in the vitellus was taken as evidence of sperm penetration.

\section{Statistical analysis}

The data were analyzed using $\chi^{2}$-test (penetration rate) or Tukey's multiple range test (percentages of motile spermatozoa and progressively motile cells and average number of spermatozoa in penetrated eggs) [21].

\section{Results and Discussion}

Fig. 2 shows the motility of spermatozoa from various regions of the epididymis. Immediately after the collection, a small population of spermatozoa from the proximal caput exhibited uncoordinated twitching and the rest were immotile. The percentage of motile spermatozoa increased to $29 \%$ in the sample from the distal caput and some of the cells exhibited intensively flagellant or circular types of movement despite having no progressive motility. In the samples from the corpus, $43-44 \%$ of spermatozoa were motile and 19-24\% moved in a forward direction. Approximately $80 \%$ of the cells from the cauda showed an intensive, forward movement. These results agree with those from a previous report [22]. Successful sperm migration to the site of fertilization and penetration into the zona pellucida of the egg require vigorous motility of a spermatozoon [23].

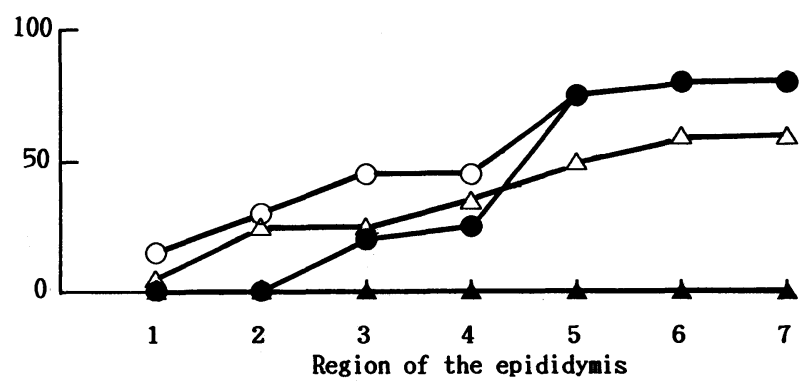

Fig. 2. Motility of spermatozoa from various regions of the epididymis $(n=3) \bigcirc$ : \% of motile spermatozoa immediately after collection : \% of progressively motile spermatozoa immediately after collection $\triangle$ : \% of motile spermatozoa after preincubation $\Delta$ : \% of progressively motile spermatozoa after preincubation. All items except percentage of progressive motile spermatozoa after preincubation show significantly higher rates in the samples from lower regions of the epididymis.
Most boar spermatozoa acquired the ability to move in a forward direction during their transit through the corpus epididymidis, which coincides with the development of sperm fertilizing ability in vivo [2]. It is probable, therefore, that low fertility of spermatozoa from the caput epididymidis is due partially to the absence of progressive motility. After preincubation, however, the percentage of motile spermatozoa decreased by $5-20 \%$ and no progressively motile cells were observed in any sample. Depressed motility has been reported also in ejaculated goat spermatozoa after preincubation under the similar conditions [24].

After coincubation with eggs for $5 \mathrm{~h}$, spermatozoa from the caput binding to the surface of the egg were easily removed by repeated aspiration of the eggs. However, epididymal spermatozoa from the more distal regions bound more firmly to the eggs. Similar results were obtained using nonpreincubated spermatozoa from Large White boars [22]. Thus, it appears that the ability to bind to egg plasma membrane is greatly developed during sperm transit through the corpus and cauda epididymidis.

Many reports are available on the penetrability of immature spermatozoa into zona-free hamster eggs from the heterologous epididymis. Human spermatozoa from the caput epididymidis consistently failed to penetrate eggs, while those from the cauda penetrated at a level approaching that found for ejaculated spermatozoa [17]. In marmoset monkeys, insemination using spermatozoa from the proximal caput resulted in no sperm-egg fusion [16]. According to the reports on rams [11, 12], spermatozoa from the caput epididymidis scarcely demonstrated penetrability into eggs under preincubation conditions with heparin or dilauroylphosphatidylcholine liposome as well as without these reagents. In goats, however, rete testicular spermatozoa preincubated in the isolated hamster uterus penetrated some eggs, although the penetration rate $(15.5 \%)$ was significantly lower than that of cells from the cauda epididymidis (95.1\%) [25].

As shown in Table 1, the penetration rates of boar spermatozoa from all regions of the epididymis examined were consistently high (95-100\%). The average number of spermatozoa in penetrated eggs (3.4-5.8) also showed no significant change in relation to sperm maturation. These results indicate that at least a proportion of boar 
Table 1. Penetrability into zona-free hamster eggs of spermatozoa from various regions of the epididymis

\begin{tabular}{ccc}
\hline $\begin{array}{c}\text { Region of } \\
\text { epididymis }\end{array}$ & $\begin{array}{c}\text { No. of eggs } \\
\text { penetrated/ } \\
\text { no. examined (\%) }\end{array}$ & $\begin{array}{c}\text { Average no. } \\
\text { of sperm in } \\
\text { penetrated eggs }\end{array}$ \\
\hline 1 & $51 / 53(96)$ & 4.1 \\
2 & $66 / 68(97)$ & 5.8 \\
3 & $59 / 59(100)$ & 3.4 \\
4 & $55 / 56(98)$ & 4.3 \\
5 & $51 / 51(100)$ & 5.6 \\
6 & $57 / 60(95)$ & 5.1 \\
7 & $53 / 53(100)$ & 4.4 \\
\hline
\end{tabular}

spermatozoa located in the proximal caput epididymidis have the ability to fuse with egg plasma membrane. These results suggest that boar spermatozoa acquire this capacity before they are capable of fertilizing an egg in vivo [2].

\section{Acknowledgments}

We thank Daiei, Inc., for supplying the Meishan boars and for their financial support. This study was supported in part by a Grant-in-Aid for encouragement of JSPS fellowships of Japanese scientists from Ministry of Education, Science and Culture of Japan.

\section{References}

1. Robaire B, Hermo L. Efferent ducts, epididymis, and vas deferens: structure, functions, and their regulation. In: Knobil E, Neill J, (eds.), The Physiology of Reproduction. New York: Raven Press; 1988: 999-1080.

2. Holtz W, Smidt D. The fertilizing capacity of epididymal spermatozoa in the pig. $J$ Reprod Fert 1976; 46: 227-229.

3. Fraser LR, Ahuja KK. Metabolic events in fertilization. Gamete Res 1988; 20: 491-519.

4. Pavlok A. Development of the penetration activity of mouse epididymal spermatozoa in vivo and in vitro. J Reprod Fert 1974; 36: 203-205.

5. Saling PM. Development of the ability to bind to zonae pellucidae during epididymal maturation: reversible immobilization of mouse spermatozoa by lanthanum. Biol Reprod 1982; 26: 429-436.

6. Lakoski KA, Carron CP, Cabot CL, Saling PM. Epididymal maturation and the acrosome reaction in mouse sperm: response to zona pellucida develops coincident with modification of M42 antigen. Biol Reprod 1988; 38: 221-233.

7. Lacham $\mathbf{O}$, Trounson $\mathbf{A}$. Fertilizing capacity of epididymal and testicular spermatozoa microinjected under the zona pellucida of the mouse oocyte. Mol Reprod Dev 1991; 29: 85-93.

8. Cuasnicú PS, Echeverría FG, Pizza A, Blaquier JA. Addition of androgens to cultured hamster epididymis increases zona recognition $\mathrm{ky}$ immature spermatozoa. J Reprod Fert 1984; 70: 541-547.

9. Brackett BG, Hall JL, Yon-kak O. In vitro fertilizing ability of testicular, epididymal and ejaculated rabbit spermatozoa. Fertil Steril 1978; 29: 571-582.

10. Fournier-Delpech S, Courtens JL, Pisselet CL,
Delaleu B, Courot M. Acquisition of zona binding by ram spermatozoa during epididymal passage, as revealed by interaction with rat oocytes. Gamete Res 1982; 5: 403-408.

11. Williams RM, Graham JK, Hammerstedt RH. Determination of the capacity of ram epididymal and ejaculated sperm to undergo the acrosome reaction and penetrate ova. Biol Reprod 1991; 44: 1080-1091.

12. Graham JK, Nolan JP, Hammerstedt RH. Effect of dilauroylphosphatidylcholine liposomes on motility, induction of the acrosome reaction, and subsequent egg penetration of ram epididymal sperm. Biol Reprod 1991; 44: 1092-1099.

13. Peterson RN, Hunt WP, Henry LH. Interaction of boar spermatozoa with porcine oocytes: increase in proteins with high affinity for zona pellucida during epididymal transit. Gamete Res 1986; 14: 57-64.

14. Yanagimachi R. Zona-free hamster egg. Their use in assessing fertilizing capacity and examining chromosomes of human spermatozoa. Gamete Res 1984; 10: 187-232.

15. Yanagimachi R. Mechanism of fertilization in mammals. In: Mastroianni L, Bissers JD, (eds.), Fertilization and Embryonic Development in vitro. New York: Plenum Press; 1981: 81-181.

16. Moore HDM. An assessment of the fertilizing ability of spermatozoa in the epididymis of the marmoset monkey (Callithrix jacchus). Int J Androl 1981; 4: 321-330.

17. Moore HDM, Hartman TD, Pryor JP. Development of the oocyte-penetrating capacity of spermatozoa in the human epididymis. Int J Androl 1983; 
6: $310-318$.

18. Kusunoki H, Kato S, Kanda S. Induction of the acrosome reaction in goat spermatozoa in simple physiological salt solution. J Exp Zool 1989; 250: 346-348.

19. Kusunoki H, Kato S, Kanda S. A new technique for the induction and detection of the acrosome reaction in boar spermatozoa. In: Proc. 5th AAAP Anim. Sci. Congr.; 1990; Taipei, Taiwan. Abstract 3: 288 .

20. Brackett BG, Oliphant G. Capacitation of rabbit spermatozoa in vitro. Biol Reprod 1975; 12: 260-274.

21. Steel RGD, Torrie JH. Principles and Procedures of Statistics. New York: McGraw-Hill Book Co; 1960 .
22. Dacheux JL, Paquignon M, Combarnous Y. Headto-head agglutination of ram and boar epididymal spermatozoa and evidence for an epididymal antagglutinin. J Reprod Fert 1983; 67: 181-189.

23. Katz DF, Drobnis EZ, Overstreet JW. Factors regulating mammalian sperm migration through the female reproductive tract and oocyte vestments. Gamete Res 1989; 22: 443-469.

24. Kusunoki H, Sakaue M, Kato S, Kanda S. Induction of the acrosome reaction in ejaculated goat spermatozoa by preincubation in chemically defined medium. J Exp Zool 1989; 249: 322-328.

25. Kato S. Characteristics of rete testicular fluid and spermatozoa collected from conscious goats and boars by cannulation. Jpn J Anim Reprod 1985; 31: 105-109 (In Japanese). 